\title{
Identifying patients at risk for postprocedural morbidity after treatment of incidental intracranial aneurysms: the role of aneurysm size and location
}

\author{
Vallabh Janardhan, M.D., Robert Friedlander, M.D., Howard Riina, M.D., \\ and Philit Edwin STieg, Ph.D., M.D. \\ Department of Neurology, Boston University School of Medicine, Boston; Cerebrovascular Center, \\ Division of Neurological Surgery, Brigham and Women's Hospital, and Harvard Medical School, \\ Boston, Massachusetts; and Department of Neurological Surgery, New York Presbyterian Hospital, \\ Weill Medical College of Cornell University, New York, New York
}

\begin{abstract}
Object. A decision to treat incidental intracranial aneurysms (IIAs) relies on understanding the risks of treatment and weighing them against the those of aneurysm rupture. Whereas the natural history of IIAs is currently being studied, the risks associated with treating IIAs and factors associated with poor outcome need to be clearly established.

Methods. In a consecutive series of 125 patients, 160 IIAs were treated either surgically (152 cases) or endovascularly (eight cases). Postprocedural morbidity was defined as a new neurological deficit associated with a score greater than or equal to 3 on the modified Rankin Scale or a score of less than 24 on the Mini-Mental Status Examination. Logistic regression analysis was used to identify predictors of postprocedural morbidity from retrospectively collected data on demographic, clinical, and radiographic characteristics.

Treatment of IIAs was not associated with any mortality and was associated with postprocedural morbidity in 17 (13.6\%) of 125 patients (early outcome) and eight (6.4\%) of patients (late outcome). In the logistic-regression model, treatment of aneurysms $(\geq 13 \mathrm{~mm}$ ) and posterior circulation aneurysms were independently associated with postprocedural morbidity. In patients in whom postprocedural neurological deficits developed, $12(70.6 \%)$ of 17 and four $(23.5 \%)$ of 17 patients harbored aneurysms with broad or calcified necks, respectively. Age, comorbidities, multiple aneurysms, specific aneurysm location, and history of subarachnoid hemorrhage related to a different aneurysm were not significantly associated with poor outcome.

Conclusions. The authors found that IIAs can be safely and effectively treated without causing mortality and with a lower morbidity rate than previously reported. A combination of radiographic variables may be helpful in identifying patients at risk for postprocedural morbidity.
\end{abstract}

\section{KEY WORDS • incidental aneurysm • asymptomatic aneurysm • intracranial aneurysm • morbidity • risk factor • outcome}

Prospective autopsy and angiographic studies have shown that the prevalence of UIAs ranges from 3.7 to $6 \%$ in the general population. ${ }^{30}$ Advances in the field of neuroimaging ${ }^{1,4,34,38}$ have led to an increase in the rate of detection of IIAs from 0.3 to $2 / 100,000$ person-years between 1965 and $1995 .{ }^{21}$ The major risk associated with not treating IIAs is aneurysmal SAH, ${ }^{15,30,40}$ which is the cause of nearly $25 \%$ of all cerebrovascular deaths. ${ }^{38}$ Despite current advances in the management of ruptured aneurysms, post-SAH outcome following has not changed. ${ }^{7}$ A mortality rate of 55\% after rupture and a rate of severe morbidi-

Abbreviations used in this paper: $\mathrm{BA}=$ basilar artery; IIA = incidental intracranial aneurysm; ISUIA = International Study on Unruptured Intracranial Aneurysms; MMSE = Mini-Mental Status Examination; $\mathrm{mRS}=$ modified Rankin Scale; $\mathrm{SAH}=$ subarachnoid hemorrhage; UIA = unruptured intracranial aneurysm. ty as high as $50 \%$ have been reported. ${ }^{11,12,39}$ Treatment of the unruptured aneurysm sac prior to rupture will prevent the complications of $\mathrm{SAH}{ }^{26}$

The treatment of IIAs, however, is not without risk, and a decision to treat depends on the risks of intervention compared with those of aneurysm rupture. ${ }^{5}$ The authors of metaanalyses have estimated the risk of rupture to be $1.9 \% / y^{2} \mathrm{r}^{30}$ and the morbidity and mortality rates associated with treatment to range from 4.1 to $10.9 \%$ and 1 to $2.6 \%$, respectively. ${ }^{20,28}$ In contrast, participants in the ISUIA have shown the risk of rupture to be lower (0.05$0.5 \% / y e a r$ ) and the risks of intervention to be higher (long-term morbidity $11.9-12.1 \%$ and mortality 1.0 $3.8 \%) .{ }^{13}$ Thus, advising a patient with an IIA about treatments remains a clinical dilemma. Although data derived from the ongoing prospective arm of the ISUIA should better clarify the natural history of IIAs, more information 
on outcome following treatment of IIAs is needed to allow adequate understanding of the risks and benefits of intervention as well as to help identify risk factors predictive of poor outcome.

This study comprises a review of our experience with 125 patients harboring 160 IIAs treated either surgically or endovascularly. All patients were evaluated independently for outcome using the mRS and the MMSE. Statistical evaluation was performed to identify predictors of treatment outcome from retrospectively collected data on demographic and clinical characteristics of patients and radiographic features of the aneurysms.

\section{CLINICAL MATERIAL AND METHODS}

\section{Patient Selection}

Data in all patients who underwent surgical or endovascular treatment of an IIA at our institution between January 1990 and December 1999 were reviewed retrospectively. An IIA was defined as an UIA that was incidentally found during neuroimaging for symptoms unrelated to the UIA (Group 1). Patients with a UIA detected at the time as an SAH from a coexisting aneurysm were also included in the study (Group 2). The ruptured aneurysms in all these patients, however, had to have been treated surgically/endovascularly at a previous date and all these patients had to be able to care for themselves (mRS score $\leq 2$ ). Patients with symptomatic UIAs (cranial nerve palsy or symptoms due to mass effect), traumatic, mycotic, and fusiform aneurysms were not included in this study.

\section{Data Collection}

Patient Characteristics. All pertinent characteristics were recorded and included age, sex, smoking history, illicit drug or alcohol use, history of SAH from a different aneurysm, family history of aneurysms, known adult polycystic kidney disease, hypertension, and ischemic heart disease; other coexisting medical illnesses such as atrial fibrillation, valvular heart disease, carotid artery disease, peripheral-vascular disease, chronic obstructive pulmonary disease, diabetes, renal insufficiency, thyroid dysfunction, and recent history of systemic malignancy. Details of the procedure performed and the results demonstrated on the postoperative angiogram (obtained in all patients) were also noted.

Aneurysm Characteristics. The presence of IIAs was confirmed in all cases by conventional four-vessel angiography. The angiograms were interpreted by neuroradiologists and reviewed independently by the primary neurosurgeon. Findings on angiography, including aneurysm size, site and number of IIAs (single/multiple) were noted. Aneurysm size (maximum fundus and neck diameter) was determined after correction for magnification. In the case of multiple aneurysms, the maximum diameter of the largest aneurysm was noted. Specific aneurysm locations were noted in all patients.

Outcome Assessment. Outcomes were assessed at 30 days (early) and 6 months postoperatively (late). Followup information was obtained by reviewing the patient's medical records, telephone survey, and clinic visit notes. All patients with poor outcomes were evaluated in the clinic. Postprocedural morbidity was defined as a new neurological deficit associated with a score of 3 or more on the mRS, ${ }^{37}$ or a score less than 24 on the MMSE. ${ }^{8}$ Treatment-related mortality was defined as death due to any cause occurring within 1 month of the procedure.

\section{Statistical Analysis}

Univariate logistic regression analysis was used to examine the effect of the 21 variables collected (demographic, clinical, and radiographic) on postprocedural morbidity. A probability value of less than 0.1 was used as an entry criterion into the multivariate model. Multivariate logistic regression analysis was used to identify predictors of postprocedural morbidity. A probability value of less than 0.05 was considered significant. StatView (Version 5.0; SAS Institute Inc., Cary, NC) statistical software was used for the analyses.

\section{RESULTS}

\section{General Features}

A total of 125 patients underwent surgical or endovascular treatment of 160 IIAs. The mean age was $52.6 \pm$ 12.3 years (range $28-83$ years) and 95 patients $(76 \%)$ were women. The majority of aneurysms in this series were in Group 1 (Fig. 1).

\section{Treatment of IIAs}

One hundred fifty-two IIAs were treated surgically. The goal of surgery was aneurysm obliteration with preservation of the parent vessel, which was achieved in 140 aneurysms; the remaining were not amenable to clipping because of broad based necks ( $>4 \mathrm{~mm}$ ), partially thrombosed/calcified necks, and proximate perforating vessels and were wrapped (10 cases) or trapped after by-pass

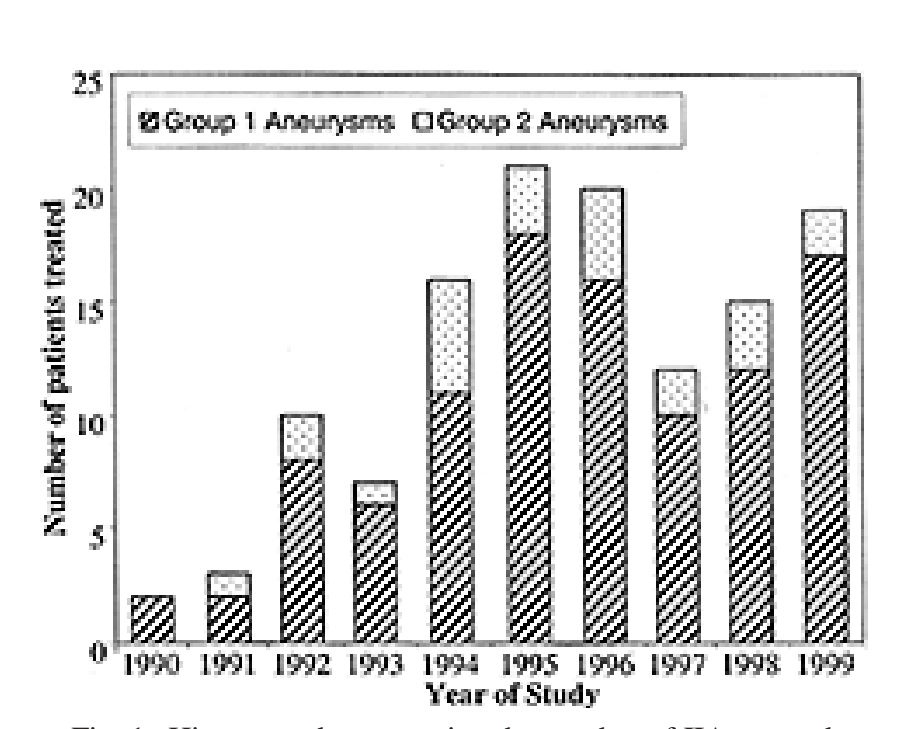

Fig. 1. Histogram demonstrating the number of IIAs treated at our institution between 1990 and 1999. The increase is more significant in patients harboring Group 1 aneurysms; the increased incidence may be an effect of recent advances in neuroimaging technology. 


\section{Incidental intracranial aneurysms}

surgery (two cases). Eight IIAs were treated endovascularly. Embolization in which Guglielmi detachable coils were placed performed in six intracavernous aneurysms and in one BA bifurcation aneurysm. One giant intracavernous aneurysm was treated with balloon occlusion of the parent vessel. Postoperative angiograms were obtained in all patients. Except the 10 aneurysms that were wrapped, complete aneurysm obliteration was noted following treatment in the remaining aneurysms. All patients in whom aneurysms were wrapped underwent follow-up examination through June 2000. Median follow-up time for these patients was 5.6 years (range $0.5-8.8$ years); no aneurysm that underwent wrapping ruptured during the follow-up period.

The treatment of IIAs was not associated with any mortality, and 117 patients $(93.6 \%)$ patients experienced good long-term (6-month) outcome. A review of all patients in whom transient/persistent neurological deficits developed following treatment of IIAs and the possible risk factors associated with poor outcome are shown in Table 1 . Because of the small number of adverse events at 6 months and the need to identify risk factors for all postprocedural neurological deficits (transient and persistent), postprocedural morbidity at 30 days was used as the dependent variable in the logistic regression analysis.

\section{Risk Factors for Postprocedural Morbidity}

Intracranial aneurysms were graded based on $\operatorname{size}^{27}$ and classified as small/medium $(<13 \mathrm{~mm})$ in $103(82.4 \%)$, large (13-24 $\mathrm{mm})$ in $18(14.4 \%)$, and giant $(>24 \mathrm{~mm})$ in four patients $(3.2 \%)$. The mean aneurysm size was $8.9 \pm$ $5.3 \mathrm{~mm}$ (range $2-30 \mathrm{~mm}$ ). For further analysis, large and giant aneurysms $(>13 \mathrm{~mm}$ ) were grouped together (22 lesions). The relationship between aneurysm size and postprocedural morbidity is shown in Table 2. The specific location of the IIAs is shown in Table 3. Univariate analysis of data obtained in patients with single aneurysms

TABLE 1

Postprocedural morbidity following treatment of IIAs*

\begin{tabular}{|c|c|c|c|c|c|c|c|c|}
\hline $\begin{array}{l}\text { Age } \\
\text { (yrs), } \\
\text { Sex }\end{array}$ & $\begin{array}{l}\text { Size } \\
(\mathrm{mm})\end{array}$ & Site & $\begin{array}{c}\text { Broad } \\
\text { Neck } \\
(>4 \mathrm{~mm})\end{array}$ & $\begin{array}{l}\text { Cal- } \\
\text { cified } \\
\text { Neck }\end{array}$ & Intraop Findings & $\begin{array}{c}\text { Early Out- } \\
\text { come (30 days) }\end{array}$ & Imaging Findings & $\begin{array}{l}\text { Late Out- } \\
\text { come (6 mos) }\end{array}$ \\
\hline $62, \mathrm{~F}$ & 18 & MCA & yes & no & $\begin{array}{l}\text { thrombectomy, } 2 \text { branches } \\
\text { of MCA came directly } \\
\text { off IIA, temp clip }\end{array}$ & $\begin{array}{l}\text { dysphasia, lt } \\
\text { hemiparesis }\end{array}$ & $\begin{array}{l}\text { 1t frontotemporal \& } \\
\text { BG ischemia/infarct }\end{array}$ & resolved; mRS 1 \\
\hline $31, \mathrm{~F}$ & 14 & AComA & yes & no & temp clip & MS changes & $\begin{array}{l}\text { initial clipping partial, } \\
\text { required reclipping }\end{array}$ & resolved completely \\
\hline $36, \mathrm{~F}$ & 6 & $\mathrm{BA}, \mathrm{SCA}$ & yes & no & $\begin{array}{l}\text { clipping of } 2 \text { posterior } \\
\text { circulation aneurysms }\end{array}$ & MS changes & thalamic infarct & resolved completely \\
\hline $75, \mathrm{~F}$ & 8 & $\mathrm{MCA}$ & yes & no & $\begin{array}{l}\text { residual AComA treated } \\
\text { earlier was also reclipped } \\
\text { temp clip }\end{array}$ & $\begin{array}{l}\text { MS changes, lt } \\
\text { hemiparesis }\end{array}$ & rt frontal hematoma & $\begin{array}{l}\text { mild cognitive de- } \\
\text { ficits, MMSE } \\
>25 ; \text { mRS } 1\end{array}$ \\
\hline $65, \mathrm{~F}$ & 8 & AComA & no & no & clipping of AComA & lt hemiparesis & rt frontal hematoma & resolved completely \\
\hline $72, \mathrm{~F}$ & 5 & ICA & no & no & $\begin{array}{l}\text { clipping of superior hypo- } \\
\text { physeal IIA }\end{array}$ & $\begin{array}{l}\text { MS changes \& bi- } \\
\text { lat hemiparesis }\end{array}$ & $\begin{array}{l}\text { bifrontal subdural } \\
\text { hematomas }\end{array}$ & resolved completely \\
\hline $42, \mathrm{~F}$ & 15 & PCoA & yes & no & temp clip & MS changes & no abnormality & resolved completely \\
\hline $52, \mathrm{~F}$ & 10 & $\mathrm{MCA}$ & yes & yes & temp clip & $\begin{array}{l}\text { dysarthria, } \mathrm{rt} \mathrm{fa-} \\
\text { cial droop, lt } \\
\text { hemiplegia }\end{array}$ & $\begin{array}{l}\text { rt frontal lobe wedge- } \\
\text { shaped infarct }\end{array}$ & $\begin{array}{l}\text { recovered function- } \\
\text { ally; mRS } 2\end{array}$ \\
\hline $51, \mathrm{~F}$ & 9 & $\begin{array}{l}\text { MCA, } \\
\text { AComA }\end{array}$ & no & no & $\begin{array}{l}\text { clipping of } 4 \text { IIAs \& wrap- } \\
\text { ping } 1 \text { IIA (temp clip) }\end{array}$ & $\begin{array}{l}\text { MS changes \& } \mathrm{rt} \\
\text { hemiparesis }\end{array}$ & no evidence of infarct & resolved completely \\
\hline $51, \mathrm{~F}$ & 21 & $\begin{array}{l}\text { MCA, } \\
\text { ICA }\end{array}$ & yes & yes & $\begin{array}{l}\text { aneurysmorrhaphy, perfor- } \\
\text { ators in back of IIA temp } \\
\text { clip }\end{array}$ & $\begin{array}{l}\text { aphasia, rt hemi- } \\
\text { paresis }\end{array}$ & lt MCA infarct & mRS 3 \\
\hline $60, \mathrm{M}$ & 8.3 & $\begin{array}{l}\text { MCA, } \\
\text { PCoA }\end{array}$ & no & no & $\begin{array}{l}\text { craniotomy } \times 2(3 \text { IIAs }) \text {, } \\
\text { temp clip }\end{array}$ & $\begin{array}{l}\text { 1t hemiplegia, rt } \\
\text { hemiparesis }\end{array}$ & $\begin{array}{l}\text { rt BG/caudate \& 1t } \\
\text { frontal infarct }\end{array}$ & mRS 5 \\
\hline $39, \mathrm{~F}$ & 7 & BA & no & no & $\begin{array}{l}\text { angiography: excellent } \\
\text { clip placement }\end{array}$ & $\begin{array}{l}\text { rt ptosis, lt hemi- } \\
\text { paresis }\end{array}$ & $\begin{array}{l}\text { posterior temporal } \\
\text { hematoma }\end{array}$ & mRS 3 \\
\hline $53, \mathrm{~F}$ & 25 & ICA & yes & no & $\begin{array}{l}\text { EC-MCA bypass \& trap- } \\
\text { ping of giant intracav- } \\
\text { ernous IIA }\end{array}$ & $\begin{array}{l}\text { aphasia, lt ptosis, } \\
\text { rt hemiparesis }\end{array}$ & $\begin{array}{l}\text { graft initially patent, } \\
\text { later got occluded, } \\
\text { lt MCA infarct }\end{array}$ & mRS 3 \\
\hline $51, \mathrm{~F}$ & 19 & $\begin{array}{l}\text { BA, } \\
\text { PCoA }\end{array}$ & yes & no & $\begin{array}{l}\text { postop angiography after } \\
\text { clipping: excellent results }\end{array}$ & $\begin{array}{l}\text { MS changes \& } \\
\text { bilat motor } \\
\text { deficits }\end{array}$ & $\begin{array}{l}\text { bilat thalamic \& mid- } \\
\text { brain infarcts }\end{array}$ & mRS 4 \\
\hline $70, \mathrm{~F}$ & 8 & MCA & yes & no & $\begin{array}{l}\text { rt frontal hematoma re- } \\
\text { quired evacuation }\end{array}$ & It hemiplegia & $\begin{array}{l}\text { venous infarcts \& rt } \\
\text { frontal hematoma }\end{array}$ & mRS 4 \\
\hline $66, \mathrm{~F}$ & 8 & BA & yes & yes & $\begin{array}{l}\text { temp clip, angiography: } \\
\text { excellent results }\end{array}$ & $\begin{array}{l}\text { aphasia, bilat mo- } \\
\text { tor deficits }\end{array}$ & $\begin{array}{l}\text { pontine \& temporal } \\
\text { lobe infarcts }\end{array}$ & mRS 4 \\
\hline $69, \mathrm{M}$ & 9.2 & ACA & yes & no & $\begin{array}{l}\text { clipping of } A_{1} \text { segment } \\
\text { IIA }\end{array}$ & $\begin{array}{l}\text { aphasia, lt hemi- } \\
\text { paresis }\end{array}$ & rt basal ganglia infarct & mRS 3 \\
\hline
\end{tabular}

* AComA = anterior communicating artery; $\mathrm{BG}=$ basal ganglia; $\mathrm{EC}=$ extracranial; $\mathrm{ICA}=$ internal carotid artery; $\mathrm{MCA}=$ middle cerebral artery; $\mathrm{MS}=$ mental status; $\mathrm{PComA}=$ posterior communicating artery; $\mathrm{SCA}=$ superior cerebellar artery; temp = temporary. 
TABLE 2

Angiographic predictors of postprocedural morbidity in 125 patients: univariate analysis*

\begin{tabular}{|c|c|c|c|c|c|}
\hline \multirow{2}{*}{$\begin{array}{l}\text { Angiographic } \\
\text { Predictors }\end{array}$} & \multirow{2}{*}{$\begin{array}{c}\text { No. of } \\
\text { Patients }(\%)\end{array}$} & \multicolumn{2}{|c|}{ No. of Patients w/ Morbidity (\%) } & \multirow{2}{*}{$\begin{array}{l}\text { Odds Ratio } \\
(95 \% \mathrm{CI})\end{array}$} & \multirow{2}{*}{$\underset{\text { Value }}{\mathrm{p}}$} \\
\hline & & Early (17) & Late (8) & & \\
\hline \multicolumn{6}{|l|}{ aneurysm size (mm) } \\
\hline$<13$ & $103(82.4)$ & $11(10.6)$ of 103 & $5(4.9)$ of 103 & $0.32(0.10-0.99)$ & $0.04 \dagger$ \\
\hline$\geq 13$ & $22(17.6)$ & $6(27.3)$ of 22 & $3(13.6)$ of 22 & & \\
\hline \multicolumn{6}{|l|}{ aneurysm site } \\
\hline anterior circulation & $113(90.4)$ & $13(11.5)$ of 113 & $5(4.4)$ of 113 & $0.26(0.07-0.99)$ & $0.04 \dagger$ \\
\hline posterior circulation & $12(9.6)$ & $4(33.3)$ of 12 & $3(25.0)$ of 12 & & \\
\hline \multicolumn{6}{|l|}{ no. of IIAs } \\
\hline single & $100(80.0)$ & $12(12.0)$ of 100 & $5(5.0)$ of 100 & $0.55(0.17-1.72)$ & 0.30 \\
\hline multiple & $25(20.0)$ & $5(25.0)$ of 25 & $3(12.0)$ of 25 & & \\
\hline
\end{tabular}

revealed that the specific location of the lesion was not significantly predictive of poor outcome (Table 3 ). Cases were also classified based on whether anterior (113 patients) or posterior circulation aneurysms (12 cases) were treated. For the analysis, patients with multiple IIAs who underwent definitive treatment for both anterior and posterior circulation aneurysms were assigned to the posterior circulation group (three cases). The relationship between aneurysm location and postprocedural morbidity is shown in Table 2. Twenty-five patients (20\%) harbored multiple IIAs, and the mean number of IIAs in these patients was $2.4 \pm 0.7$ (range 2-5). Univariate analysis revealed that the number of IIAs treated was not significantly predictive of poor outcome (Table 2).

Statistical analysis was performed to identify predictors of treatment outcome. Fifteen patients (12\%) were 70 years of age or older. Demographic and clinical characteristics were not predictive of postprocedural morbidity (Table 4). Multivariate logistic regression analysis indicated that treatment of aneurysms $13 \mathrm{~mm}$ or larger and posterior circulation aneurysms were independent determinants of postprocedural morbidity (Table 5). Aneurysms that were less than $13 \mathrm{~mm}$ in largest diameter tended to be associated with more favorable outcomes compared with large aneurysms ( $\geq 13 \mathrm{~mm}$ ) (Table 5), and anterior circulation aneurysms tended to be associated with better outcomes compared with posterior circulation aneurysms (Table 5).

\section{DISCUSSION}

\section{Overview and Salient Features}

Greater availability of noninvasive neuroimaging $1,4,34,38$ has led to an increase in the detection of IIAs. ${ }^{21}$ Rupture of IIAs and the subsequent complications of SAH can be prevented by early treatment. The treatment of IIAs, however, is not without risk. Although morbidity and mortality associated with surgical management of unruptured aneurysms have been documented in several studies, the range of reported values is wide $(0-16.7 \%$ for morbidity and $0-7.7 \%$ for mortality), ${ }^{13,20,28}$ and the risk factors associated with poor outcome have not been clearly defined. ${ }^{35}$ In the present series we found that IIAs can be safely and effectively treated without mortality and low morbidity.
Moreover, a combination of neuroimaging variablesnamely, aneurysm size and location-can be helpful in identifying those patients at increased risk for poor outcome.

\section{Natural History of IIAs}

Treatment of IIAs may be recommended after weighing the relative risks of observation compared with the morbidity associated with intervention. Jane, et al., ${ }^{14}$ and Winn, et al., ${ }^{42}$ have shown that the annual risk of rupture of IIAs is around 1\%. The ISUIA has shown that the annual risk of rupture is approximately $1 \%$ only for aneurysms greater than or equal to $10 \mathrm{~mm}$ and that aneurysms less than $10 \mathrm{~mm}$ have a negligible risk of rupture $(0.05 \% /$ year in Group 1 and 0.5\%/year in Group 2 aneurysms). ${ }^{13}$ In contrast, Rinkel, et al., ${ }^{31}$ in their systematic review of all natural history studies conducted between 1955 and 1996, found that the overall annual rupture rate for UIAs is $1.9 \%$ (4\%/year for aneurysms $\geq 10 \mathrm{~mm}$ and $0.7 \%$ /year for aneurysms $<10 \mathrm{~mm}$ ). ${ }^{30}$ The discrepancy in the aneurysmal rupture rates between the systematic review and the ISUIA has been partly attributed to the shorter followup period of 8.3 years in the ISUIA compared with the 13.9-year period of Juvela, et al. ${ }^{15}$ Additional data from the prospective arm of the ISUIA should help resolve the above issue.

Juvela, et al., ${ }^{16}$ have recently reported data on the longterm natural history of UIAs. In a series of 142 patients with 181 UIAs (median follow-up time) 19.7 years, range 0.8-38.9 years, they estimated the overall annual risk of rupture to be $1.3 \%$ (2.8\%/year for aneurysms $\geq 10 \mathrm{~mm}$ and 1.1-2.3\%/year for aneurysms $<10 \mathrm{~mm}$ ) and a cumulative risk of rupture of $10.5 \%$ at 10 years. In their series, because 131 of 142 patients harbored Group 2 aneurysms, data on the annual risk of rupture of Group 1 aneurysms is limited. Tsutsumi, et al., ${ }^{36}$ in a community-based followup study, have attempted to address the issue of the risk of rupture in Group 1 aneurysms. In their series of 62 patients with 83 IIAs (mean follow-up time of 4.3 years, range $0.5-17$ years), they estimated the cumulative risk of rupture of IIAs at 10 years to be $22.1 \%$ (55.9\%/10 years for aneurysms $\geq 10 \mathrm{~mm}$ and $22.1 \% / 10$ years for aneurysms $<10 \mathrm{~mm}$ ). Evaluation of results obtained in these 
Incidental intracranial aneurysms

TABLE 3

Aneurysm location and outcome in 100 patients with IIAs: univariate analysis*

\begin{tabular}{|c|c|c|c|c|c|c|c|}
\hline \multirow{2}{*}{$\begin{array}{c}\text { Specific } \\
\text { Aneurysm Location }\end{array}$} & \multicolumn{3}{|c|}{ Frequency of IIAs Based on Location } & \multicolumn{2}{|c|}{ Outcome of Single IIAs \& Morbidity } & \multirow{2}{*}{$\begin{array}{l}\text { Odds Ratio } \\
(95 \% \text { CI) }\end{array}$} & \multirow{2}{*}{$\begin{array}{c}\mathrm{p} \\
\text { Value }\end{array}$} \\
\hline & All (160) & Multiple (60) & Single (100) & Early (12) & Late (7) & & \\
\hline ACA \& AComA & 27 & 7 & 20 & 3 & 1 & $0.7(0.2-2.9)$ & 0.6 \\
\hline MCA & 47 & 18 & 29 & 4 & 3 & $0.8(0.2-2.9)$ & 0.7 \\
\hline ICA (total) & 72 & 28 & 44 & 3 & 1 & $2.6(0.7-10.3)$ & 0.2 \\
\hline cavernous & 8 & 3 & 5 & 1 & 1 & $0.5(0.05-5.1)$ & 0.6 \\
\hline paraclinoid & 27 & 10 & 17 & 1 & 0 & $2.4(0.3-20.3)$ & 0.4 \\
\hline anterior choroid & 6 & 4 & 2 & 0 & 0 & 0 & - \\
\hline PComA & 21 & 8 & 13 & 1 & 0 & $1.7(0.2-14.7)$ & 0.6 \\
\hline bifurcation & 10 & 3 & 7 & 0 & 0 & 0 & - \\
\hline posterior circulation IIAs (total) ${ }^{\dagger}$ & 14 & 7 & 7 & 2 & 2 & $0.3(0.1-1.8)$ & 0.2 \\
\hline BA & 10 & 4 & 6 & 2 & 2 & $0.2(0.04-1.5)$ & 0.1 \\
\hline SCA & 2 & 2 & 0 & 0 & 0 & 0 & - \\
\hline PICA & 1 & 1 & 0 & 0 & 0 & 0 & - \\
\hline PCA & 1 & 0 & 1 & 0 & 0 & 0 & - \\
\hline
\end{tabular}

* ACA = anterior cerebral artery; paraclinoid = supraclinoidal and ophthalmic locations; PICA = posterior inferior cerebellar artery; PCA = posterior cerebral artery; $-=$ not applicable.

$\dagger$ Major aneurysm location groups: ICA-total $=$ cavernous + paraclinoid + anterior choroidal + PComA + ICA bifurcation; posterior circulation IIAs $=$ $\mathrm{BA}+\mathrm{SCA}+\mathrm{PICA}+\mathrm{PCA}$.

recent studies indicates that the annual risk of rupture of Group 1 and 2 aneurysms is much higher than reported in the ISUIA ${ }^{13}$ and correlates more favorably with previously reported data. ${ }^{14,15,30,42}$

It has been suggested that aneurysm size is an important determinant in risk for rupture. ${ }^{13,18}$ In previous studies by Wiebers, et al., ${ }^{40,41}$ findings were similar to those in the ISUIA, ${ }^{13}$ suggesting that the critical size limit for subsequent rupture is $10 \mathrm{~mm}$. Numerous authors have shown, however, that even small UIAs $(<5 \mathrm{~mm})$ are not innocuous and can also rupture..$^{33,44,45}$ Juvela, et al., ${ }^{16}$ have recently reported that 23 of 33 aneurysms that ruptured were initially $6 \mathrm{~mm}$ or less in size. Juvela, et al., ${ }^{15,16}$ have shown that aneurysm size was in fact an important risk factor for rupture, as were age and active smoking status, but could not identify any critical size limit for subsequent rupture and have suggested that all patients with UIAs be offered treatment irrespective of aneurysm size (if technically possible and if age and clinical condition permit).

\section{Treatment-Related Risks}

Treatment of IIAs is not without risk. To study the risks of intervention, King, et al., ${ }^{19}$ performed a metaanalysis of all outcome studies on IIAs conducted between 1966 and 1992 and showed that the morbidity and mortality rates associated with treatment were 4.1 and $1 \%$, respectively. In another metaanalysis, the morbidity and mortality rates associated with treating UIAs were 10.9 and $2.6 \%$, respectively. ${ }^{28}$ The higher rates of morbidity and mortality in this metaanlaysis have been attributed to the relatively higher percentage of patients with giant and posterior circulation aneurysms as well as the inclusion of patients with symptomatic aneurysms. The recent results of the ISUIA suggest that the postprocedural morbidity and mortality rates could be as high as 11.9 to 12.1 and 1 to $3.8 \%$, respectively. ${ }^{13}$ These authors have attributed the higher risks of intervention to the additional inclusion of impaired mental status in their overall assessment of functional out- come. The results in the present series, in which patients were evaluated by an independent observer other than the primary neurosurgeon and standardized neurological outcome scales were applied, indicate a postprocedural morbidity rate at 6 months of $6.4 \%$ (eight cases) and no mortality. This is less than that reported in the ISUIA and compares favorably with the outcomes in previous studies. ${ }^{10,20,22,25,26,31,32,43}$ In addition, half the patients with postprocedural neurological deficits at 30 days subsequently recovered to their functional baseline. Cognitive impairment as an independent factor was not significantly associated with postprocedural morbidity at 6 months.

\section{Risk factors for Postprocedural Morbidity}

Our findings suggests that treatment of large $(\geq 13$ $\mathrm{mm}$ ) and posterior circulation aneurysms were independently associated with poor outcome. The authors of several studies have shown that aneurysm size is an important determinant of surgery-related outcome. ${ }^{13,22,25,28}$ Khanna, et al., ${ }^{19}$ have shown that a $25-\mathrm{mm}$ aneurysm has a fourfold higher risk of poor outcome after surgery compared with a 5-mm aneurysm. The increased risk of postprocedural neurological deficits in patients with large aneurysms is multifactorial and related to the technical intraoperative difficulties including limited manipulation space, the need for temporary clipping, and the risks of prolonged occlusion, proximate perforating vessels, broad/atherosclerotic/calcified necks, and an increased risk of intraluminal thrombosis. ${ }^{9,24}$

The location of the aneurysm is also an important predictor of poor outcome as shown in the present study. Posterior circulation aneurysms, in particular, tend to be associated with worse outcomes. ${ }^{19,25,28}$ This has been attributed to limited surgical accessibility, close apposition to cranial nerves, and multiple perforators. ${ }^{2,29}$ Rice, et al., ${ }^{29}$ have reported a combined $4.2 \%$ morbidity and mortality rate associated with the treatment of nongiant posterior circulation aneurysms. Raaymakers, et al., ${ }^{27}$ have shown 
TABLE 4

Demographic and clinical predictors of postprocedural morbidity: univariate analysis*

\begin{tabular}{|c|c|c|c|c|c|}
\hline \multirow[b]{2}{*}{ Demographic \& Clinical Predictors } & \multirow{2}{*}{$\begin{array}{l}\text { Total No. } \\
\text { of Patients }\end{array}$} & \multicolumn{2}{|c|}{ No. W/ Morbidity } & \multirow{2}{*}{$\begin{array}{l}\text { Odds Ratio }(95 \% \mathrm{CI}) \\
\text { at Early Outcome }\end{array}$} & \multirow{2}{*}{$\begin{array}{c}\mathrm{p} \\
\text { Value }\end{array}$} \\
\hline & & Early (17) & Late (8) & & \\
\hline age $($ mean $\pm \mathrm{SD})$ & $52.6 \pm 12.3$ & & & $1(0.9-1)$ & 0.3 \\
\hline female sex & 95 & 15 & 6 & $2.6(0.6-12.2)$ & 0.2 \\
\hline cigarette smoking $\dagger$ & 36 & 6 & 1 & $0.7(0.2-2)$ & 0.5 \\
\hline use of alcohol/stimulants & 8 & 0 & 0 & 0 & - \\
\hline history of SAH & 23 & 3 & 0 & $1.1(0.3-4)$ & 0.9 \\
\hline family history of intracranial aneurysms & 15 & 1 & 1 & $2.4(0.3-19.4)$ & 0.4 \\
\hline adult polycystic kidney disease & 2 & 0 & 0 & 0 & - \\
\hline hypertension & 48 & 8 & 5 & $0.7(0.2-1.9)$ & 0.4 \\
\hline ischemic heart disease & 9 & 0 & 0 & 0 & - \\
\hline atrial fibrillation & 4 & 1 & 1 & $0.5(0.1-4.7)$ & 0.5 \\
\hline valvular heart disease & 2 & 0 & 0 & 0 & - \\
\hline carotid artery disease & 13 & 2 & 1 & $0.9(0.2-4.2)$ & 0.8 \\
\hline peripheral vascular disease & 9 & 0 & 0 & 0 & - \\
\hline chronic obstructive pulmonary disease & 13 & 1 & 0 & $2(0.2-16.5)$ & 0.5 \\
\hline diabetes & 4 & 1 & 0 & $0.5(0.1-4.7)$ & 0.5 \\
\hline renal insufficiency & 2 & 0 & 0 & 0 & - \\
\hline hypothyroidism & 11 & 3 & 1 & $0.4(0.1-1.6)$ & 0.2 \\
\hline history of malignancy & 13 & 1 & 0 & $2(0.2-16.5)$ & 0.5 \\
\hline
\end{tabular}

* $\mathrm{SD}=$ standard deviation.

$\dagger$ At any given time.

\$ First- and second-degree relatives.

that the morbidity and mortality rates associated with treating nongiant anterior circulation aneurysms are 1.9 and $0.8 \%$, respectively, and for giant posterior circulation aneurysms are 37.9 and $9.6 \%$, respectively. The results in the present series support the previous findings that posterior circulation aneurysms have poorer surgery-related outcomes. ${ }^{2,3,19,28}$ Because of the small sample size, however, adequate data could not be derived for specific aneurysm locations.

It has been suggested that surgery-related outcome is associated with the number of IIAs harbored by the patient. $^{25}$ Excessive brain manipulation was cited as the cause. ${ }^{25}$ No such association could be identified in the current series of 25 patients with multiple IIAs.

Age of the patient has been suggested as an independent

TABLE 5

Independent risk factors for postprocedural morbidity: multivariate logistic regression analysis

\begin{tabular}{lcccc}
\hline \hline & \multicolumn{2}{l}{ Logistic Regression } & & \\
\cline { 2 - 3 } & $\begin{array}{c}\text { Coef- } \\
\text { ficient }\end{array}$ & $\begin{array}{c}\text { Standard } \\
\text { Eisk Factor }\end{array}$ & $\begin{array}{c}\text { Odds Ratio* } \\
(95 \% \mathrm{CI})\end{array}$ & $\begin{array}{c}\mathrm{p} \\
\text { Value }\end{array}$ \\
\hline $\begin{array}{l}\text { aneurysm size } \\
<13 \mathrm{~mm} \text { vs } \leq 13 \mathrm{~mm}^{\dagger}\end{array}$ & -1.21 & -2.04 & $0.29(0.09-0.96)$ & $0.041^{\ddagger}$ \\
$\begin{array}{c}\text { aneurysm site } \\
\text { anterior vs. posterior } \\
\text { circulation }\end{array}$ & -1.43 & -2.03 & $0.24(0.06-0.95)$ & $0.042^{\dagger}$ \\
\hline
\end{tabular}

* Calculated using postprocedural morbidity at the time of discharge as the dependent variable.

$\dagger$ Negative value suggests the inverse relationship between treatment of anterior circulation aneurysms less than $13 \mathrm{~mm}$ and postprocedural morbidity.

\$ Statistically significant. predictor of poor outcome. ${ }^{13,19}$ Kashiwagi, et al. ${ }^{17}$ have reported good outcomes in elderly patients $(\geq 70$ years of age) who underwent elective neck clipping and suggest that surgery for patients with UIAs should not be withheld on the basis of age alone. Juvela, et al., ${ }^{16}$ have shown that age is inversely related to aneurysm rupture and that young and middle-aged adults $(<50$ years) with UIAs should be treated surgically, irrespective of aneurysm size. The median age of patients in their study was 41.9 (range 14.6-60.7 years) and even in patients greater than age 50 years they found that the 10-year cumulative risk of rupture was $15 \%$, thus suggesting the potential benefit of surgical treatment in elderly patients - if technically possible and if concurrent medical illnesses do not increase surgical risk. ${ }^{15,16}$ Although age and coexisting medical illnesses were not directly related to poor outcome in the present series, the life expectancy and the severity of comorbid illnesses should play a part in the decision-making process, and the suitability of treating IIAs in elderly patients with comorbidities should be considered on an individual basis. ${ }^{5}$

Factors other than aneurysm size and location may influence adverse outcome, demonstrated by the fact that 11 (10.6\%) of 103 patients with aneurysms less than $13 \mathrm{~mm}$ in size and $13(11.5 \%)$ of 113 patients with anterior circulation aneurysms also suffered postprocedural neurological deficits. In the present series, 12 (70.6\%) and four $(23.5 \%)$ of 17 patients with postprocedural neurological deficits harbored aneurysms with broad $(>4 \mathrm{~mm})$ and calcified necks, respectively. Ohno, et al., ${ }^{24}$ have documented ischemic complications associated with treating calcified-neck aneurysms and observed that these aneurysms are also more likely to be broad necked. These ischemic complications have been attributed to kinking/ stenosis of the parent artery by clipping, possible injury 
of the parent artery during dissection and migration of thrombi from the aneurysm. Computerized tomography angiography seems to be increasingly used for better demonstration of these broad-necked and calcified aneurysms. ${ }^{34}$ Broad-necked aneurysms are also technically more difficult to treat surgically or endovascularly. ${ }^{23,24} \mathrm{Du}-$ al-modality treatment in which surgical and endovascular methods are used has been proposed. ${ }^{6}$ Further prospective studies are needed to validate the predictive significance of these neuroimaging variables.

\section{CONCLUSIONS}

Intracranial aneurysms can be safely and effectively treated with fewer risks than previously reported. ${ }^{13} \mathrm{~A}$ combination of neuroimaging variables-namely, aneurysm size and location-may be helpful in identifying patients at risk for postprocedural morbidity. A decision to treat an IIA ultimately depends on weighing the relative risks of subsequent aneurysm rupture and the risks of intervention. Although the risks of intervention have been documented, the natural history of IIAs remains unclear, and data from the prospective arm of the ongoing ISUIA should help address this issue.

\section{Acknowledgments}

The authors thank Carlos S. Kase, M.D. and Adnan I. Qureshi, M.D. for their valuable suggestions and for reviewing the manuscript.

\section{References}

1. Atlas SW: Magnetic resonance imaging of intracranial aneurysms. Neuroimaging Clin N Am 7:709-720, 1997

2. Batjer HH, Samson DS: Causes of morbidity and mortality from surgery of aneurysms of the distal basilar artery. Neurosurgery 25:904-916, 1989

3. Batjer HH, Stieg PE, Schwartz RB: A case of acute vertigo with incidental aneurysms. Neurosurgery 36:827-33, 1995

4. Brown JH, Lustrin ES, Lev MH, et al: Characterization of intracranial aneurysms using CT angiography. AJR 169:889-893, 1997

5. Caplan LR: Should intracranial aneurysms be treated before they rupture? N Engl J Med 339:1174-1175, 1998

6. Cockroft KM, Marks MP, Steinberg GK: Planned direct dual modality treatment of complex broad-necked intracranial aneurysms: four technical case reports. Neurosurgery 46:226-230, 2000

7. Fogelholm R, Hernesniemi J, Vapalahti M: Impact of early surgery on outcome after aneurysmal subarachnoid hemorrhage. A population-based study. Stroke 24:1649-1654, 1993

8. Folstein MF, Folstein SE, McHugh PR: "Mini-Mental State." A practical method for grading the cognitive state of patients for the clinician. J Psychiatr Res 12:189-198, 1975

9. Gewirtz RJ, Awad IA: Giant aneurysms of the anterior circle of Willis: management outcome of open microsurgical treatment. Surg Neurol 45:409-421, 1996

10. Heiskanen O, Poranen A: Surgery of incidental intracranial aneurysms. Surg Neurol 28:432-436, 1987

11. Hijdra A, Braakman R, van Gijn J, et al: Aneurysmal subarachnoid hemorrhage: complications and outcome in a hospital population. Stroke 18:1061-1067, 1987

12. Hop JW, Rinkel GJ, Algra A, et al: Case-fatality rates and functional outcome after subarachnoid hemorrhage: a systematic review. Stroke 28:660-664, 1997
13. The International Study of Unruptured Intracranial Aneurysms Investigators: unruptured intracranial aneurysms - risk of rupture and risks of surgical intervention. N Engl J Med 339: 1725-1733, 1998

14. Jane JA, Kassell NF, Torner JC, et al: The natural history of aneurysms and arteriovenous malformations. J Neurosurg 62: 321-323, 1985

15. Juvela S, Porras M, Heiskanen O: Natural history of unruptured intracranial aneurysms: a long-term follow-up study. J Neurosurg 79:174-182, 1993

16. Juvela S, Porras M, Poussa K: Natural history of unruptured intracranial aneurysms: probability of and risk factors for aneurysm rupture. J Neurosurg 93:379-387, 2000

17. Kashiwagi S, Yamashita K, Kato S, et al: Elective neck clipping for unruptured aneurysms in elderly patients. Surg Neurol 53: 14-20, 2000

18. Kassell NF, Torner JC: Size of intracranial aneurysms. Neurosurgery 12:291-297, 1983

19. Khanna RK, Malik GM, Qureshi N: Predicting outcome following treatment of unruptured intracranial aneurysms: a proposed grading system. J Neurosurg 84:49-54, 1996

20. King JT Jr, Berlin JA, Flamm ES: Morbidity and mortality from elective surgery for asymptomatic, unruptured, intracranial aneurysms: a meta-analysis. J Neurosurg 81:837-842, 1994

21. Menghini VV, Brown RD Jr, Sicks JD, et al: Incidence and prevalence of intracranial aneurysms and hemorrhage in Olmsted county, Minnesota, 1965 to 1995. Neurology 51:405-411, 1998

22. Mizoi K, Yoshimoto T, Nagamine Y, et al: How to treat incidental cerebral aneurysms: a review of 139 consecutive cases. Surg Neurol 44:114-121, 1995

23. Murayama Y, Viñuela F, Duckwiler GR, et al: Embolization of incidental cerebral aneurysms by using the Guglielmi detachable coil system. J Neurosurg 90:207-214, 1999

24. Ohno K, Arai T, Isotani E, et al: Ischaemic complication following obliteration of unruptured cerebral aneurysms with atherosclerotic or calcified neck. Acta Neurochir 141:699-706, 1999

25. Orz YI, Hongo K, Tanaka Y, et al: Risks of surgery for patients with unruptured intracranial aneurysms. Surg Neurol 53: 21-29, 2000

26. Piepgras DG: Management of incidental intracranial aneurysms. Clin Neurosurg. 35:511-518, 1989

27. Qureshi AI, Sung GY, Suri MF, et al: Factors associated with aneurysm size in patients with subarachnoid hemorrhage: effect of smoking and aneurysm location. Neurosurgery 46:44-50, 2000

28. Raaymakers TW, Rinkel GJ, Limburg M, et al: Mortality and morbidity of surgery for unruptured intracranial aneurysms: a meta-anlaysis. Stroke 29:1531-1538, 1998

29. Rice BJ, Peerless SJ, Drake CG: Surgical treatment of unruptured aneurysms of the posterior circulation. J Neurosurg 73: $165-173,1990$

30. Rinkel GJ, Djibuti M, Algra A, et al: Prevalence and risk of rupture of intracranial aneurysms: a systematic review. Stroke 29: 251-256, 1998

31. Salazar JL: Surgical treatment of asymptomatic and incidental intracranial aneurysms. J Neurosurg 53:20-21, 1980

32. Samson DS, Hodosh RM, Clark WK: Surgical management of unruptured asymptomatic aneurysms. J Neurosurg 46: 731-734, 1977

33. Schievink WI, Piepgras DG, Wirth FP: Rupture of previously documented small asymptomatic saccular intracranial aneurysms. J Neurosurg 76:1019-1024, 1992

34. Schwartz RB, Tice HM, Hooten SM, et al: Evaluation of cerebral aneurysms with helical CT: correlation with conventional angiography and MR angiography. Radiology 192:717-722, 1994

35. Stieg PE, Friedlander R: Unruptured intracranial aneurysms. N Engl J Med 340:1441, 1999 
36. Tsutsumi K, Ueki K, Morita A, et al: Risk of rupture from incidental cerebral aneurysms. J Neurosurg 93:550-553, 2000

37. Van Swieten JC, Koudstaal PJ, Visser MC, et al: Interobserver agreement for the assessment of handicap in stroke patients. Stroke 19:604-607, 1988

38. Wardlaw JM, White PM: The detection and management of unruptured intracranial aneurysms. Brain 123:205-221, 2000

39. Whisnant JP, Phillips LH II, Sundt TM Jr: Aneurysmal subarachnoid hemorrhage: timing of surgery and mortality. Mayo Clin Proc 57:471-475, 1982

40. Wiebers DO, Whisnant JP, O'Fallon WM: The natural history of unruptured intracranial aneurysms. N Engl J Med 304: 696-698, 1981

41. Wiebers DO, Whisnant JP, Sundt TM Jr, et al: The significance of unruptured intracranial saccular aneurysms. J Neurosurg 66:23-29, 1987

42. Winn HR, Almaani WS, Berga SL, et al: The long-term outcome in patients with multiple aneurysms. Incidence of late hemorrhage and implications for treatment of incidental aneurysms. J Neurosurg 59:642-651, 1983
43. Wirth FP, Laws ER Jr, Piepgras D, et al: Surgical treatment of incidental intracranial aneurysms. Neurosurgery 12:507-511, 1983

44. Yasui N, Magarisawa S, Suzuki A, et al: Subarachnoid hemorrhage caused by previously diagnosed, previously unruptured intracranial aneurysms: a retrospective analysis of 25 cases. Neurosurgery 39:1096-1101, 1996

45. Young B, Meacham WF, Allen JH: Documented enlargement and rupture of a small arterial sacculation. Case report. J Neurosurg 34:814-817, 1971

Manuscript received June 12, 2002.

Accepted in final form August 23, 2002.

This paper was presented in part at the 50th Annual meeting of the Congress of Neurological Surgeons, September 25, 2000, San Antonio, Texas.

Address reprint requests to: Philip Edwin Stieg, Ph.D., MD., Department of Neurosurgery, 520 E 70th Street, New York Presbyterian Hospital, Starr 651, New York, New York 10021. email: pes2008@med.cornell.edu. 